\title{
Metodyka wyboru dróg przewozu ladunków w transporcie kolejowym
}

\begin{abstract}
W pracy zaprezentowano nowe podejście do wyznaczania dróg przewozu ladunków $w$ transporcie kolejowym. Podejście to uwzględnia nieliniowa funkcję nakładów i dodatkowe ograniczenia technologiczne, zadane w formie jawnej i niejawnej. Przedstawiono wykresy nieliniowych funkcji kar i funkcji naktadów, jako ważnych narzędzi opisujących czynniki subiektywne, wystęujace w zadaniu wyboru marszrut dla ładunków w transporcie kolejowym.
\end{abstract}

Zadaniem systemu transportowego, w zakresie obsługi ładunków, jest ich przemieszczanie w czasie, od punktów nadania do punktów przeznaczenia, wraz $\mathrm{z}$ przeróbką w punktach tranzytowych. Optymalne jego funkcjonowanie określone jest minimalnymi nakładami, dotyczącymi tego przemieszczania i przeróbki, przy uwzględnieniu ograniczeń nałożonych na zdolności przepustowe i przeróbcze elementów sieci transportowej. Tak sformułowane zadanie można zaliczyć do klasy zadań optymalizacji dynamicznej. Trudności wokół jego rozwiązania, związane są zarówno z poszukiwaniem decyzji optymalnych, jak i z realizacją tych decyzji w procesie sterowania. Jest ono możliwe jedynie po spełnieniu określonych warunków i przyjęciu pewnych uproszczeń wynikających ze specyfiki konkretnych zadań sterowania potokami transportowymi.

Bardzo często w badaniach dotyczących funkcjonowania systemów transportowych pomija się niestacjonarność potoków [7,13], przyjmując ich wielkości, korespondujące pomiędzy punktami nadania i przeznaczenia $\mathrm{w}$ określonym przedziale czasowym, jako stałe. $\mathrm{Z}$ tego wynika, że wielkość potoków transportowych pozostaje niezmienna na przestrzeni całej marszruty, od punktu nadania do punktu przeznaczenia. Przy braku ograniczeń, związanych z przepustowością elementów sieci, zadanie optymalnego rozkładu potoków dekomponuje się na proste podzadania poszukiwania najkrótszej drogi dla każdej relacji. W przeciążonych sieciach transportowych uwzględnienie ograniczeń, dotyczących obciążeń jej elementów, ma znaczenie pierwszoplanowe i w sposób istotny komplikuje wybór marszruty. Trudności te wynikają z faktu, że drogi przewozu, określone przy równomiernym obciążeniu elementów sieci transportowej znacznie różnią się od marszrut najkrótszych.

Problem wyboru dróg przewozu dla potoków ładunków w transporcie kolejowym z uwzględnieniem ograniczeń dotyczących obciążenia elementów sieci pojawia się $\mathrm{w}$ wielu kierunkach badań, do których można zaliczyć:
1. Opracowanie i korekta operatywna planu zestawienia pociagów towarowych, z uwzględnieniem ograniczeń dotyczących zdolności przepustowej szlaków i zdolności przeróbczej stacji;

2. Wybór marszruty dla potoków wagonów w planowaniu operatywnym procesu przewozowego, $\mathrm{z}$ uwzględnieniem ograniczeń dodatkowych (normy naładunku, ilość lokomotyw i drużyn trakcyjnych, obciążenie szlaków i linii itp.);

3. Wybór optymalnego wariantu perspektywicznego rozwoju sieci transportowej;

4. Poszukiwanie marszrut spełniających warunki przejścia przez zadane elementy sieci transportowej (stacje, szlaki, odcinki);

5. Synchronizacja systemów produkcyjno-transportowych, poprzez uwzględnienie zależności czasu obróbki wagonów od ich liczby;

6. Przesuw wagonów próżnych.

W szerokim spektrum tych problemów można wyróżnić dwa kierunki badań. Kierunek pierwszy dotyczy wyboru marszrut optymalnych uwzględniających zdolności przepustowe i przeróbcze elementów sieci kolejowej. Kierunek drugi wynika z konieczności racjonalnego, kompleksowego opisania strukturami informacyjnymi istniejących marszrut, wybranych na podstawie ekspertyz. Należy podkreślić, że drugi kierunek badań może mieć rozwiązanie zadowalające, jeśli drogi najkrótsze przedstawimy w postaci macierzy wierzchołków poprzedzających i następujących po nich.

Podstawą rozwiązania zagadnienia, sformułowanego w pierwszym kierunku badań, jest przyjęcie ograniczeń, dotyczących zdolności przepustowej i przeróbczej elementów sieci w sposób jawny lub niejawny. Najbardziej interesujące i naturalne jest przedstawienie ograniczeń w sposób niejawny, w postaci nieliniowej funkcji nakładów, zależnej od obciążeń elementów sieci, stanowiących sumaryczne wielkości potoków ładunków, przemieszczanych przez te elementy. Funkcja nakładów wzrasta gwałtownie, gdy obciążenia elementów sieci osiągają lub zbliżają się do 
wartości dopuszczalnej zdolności przepustowej lub przeróbczej. Sformułowane $\mathrm{w}$ ten sposób zadanie należy do klasy zadań programowania nieliniowego, w którym ograniczenia zadane są w sposób niejawny. Zależność nakładów od obciążenia $N_{i}$ elementu $i$ jest ciągła, różniczkowalną i wypukłą funkcją niemalejąca, którą można interpretować jako karę za „,przybliżanie” się do ograniczenia zdolności przepustowej lub przeróbczej [9].

Do podstawowych nieliniowych funkcji nakładów w transporcie kolejowym, związanych z planem zestawiania pociąów towarowych, należy zaliczyć zależność oszczędności czasu, związaną z przejściem jednego wagonu przez stacje bez przeróbki od ilości wagonów przerabianych na tej stacji. Postać tej zależności $\left(t_{e k}\right)$ określona jest cyklem pracy górki rozrządowej, liczbą lokomotyw manewrowych pracujących na torach wyciągowych oraz średnią wielkością przerabianych składów pociągów [1,7,9]. Zależność $t_{e k}$ można w sposób przybliżony aproksymować wielomianem stopnia drugiego.

Wiadome jest, iż czas przeróbki $t_{j}$ na $j-$ tej stacji jest funkcją wyposażenia technicznego tej stacji $f_{j}$ i potoku wagonów $N_{j}$ przerabianych na tej stacji: $t_{j}=t_{j}\left(N_{j}, f_{j}\right)$.

Analogicznie, czas jazdy na szlaku zależy od wyposażenia technicznego tego szlaku $f_{i j}$ oraz sumarycznego potoku wagonów przemieszczanych po tym szlaku:

$$
N^{i j}=\sum_{k, l} N_{k, l}^{i j} ; t_{i j}^{G}=t_{i j}\left(N^{i j}, f_{i j}\right)
$$

gdzie: $N_{k, l}^{i j}$ - część potoku wagonów $N_{k, l}$ przemieszczana po szlaku $(i, j) ; k, l=\overline{1, n}, k \neq l$.

Przedstawione funkcje monotonicznie maleją względem $f\left(\frac{\partial t}{\partial f} \leq 0\right)$ i monotonicznie rosną wzglę$\operatorname{dem} N\left(\frac{\partial t}{\partial N} \geq 0\right)$. Wartość $t_{j}$ rośnie do nieskończoności, jeżeli $N$ zdecydowanie przewyższa $f$ :

$$
\lim _{N / t \rightarrow \infty} t=\infty .
$$

Przy zadanym wyposażeniu technicznym stacji i szlaków, czas jazdy i przeróbki rośnie wraz ze wzrostem potoku. Z tego wynika, że rozpatrywane czasy mogą być przedstawione w postaci niemalejących funkcji wypukłych, zależnych od wielkości potoku wagonów.

Zauważmy, że dla uproszczenia dalszych obliczeń funkcję $t$ można z powodzeniem aproksymować za pomocą odcinkowo-liniowych funkcji wypukłych. I tak, funkcję czasu jazdy jednego wagonu, w zależności od przerabianego potoku, można aproksymować następująco: $t_{i j}=a_{i j} N_{i j}+b_{i j}$, gdzie wielkość $a_{i j}$ charakteryzuje tempo wzrostu czasu jazdy, przy wzroście potoku na danym szlaku $(i, j)$. Funkcja ta może przyjąć dwie wartości: $a_{i j}^{\max }$ lub $a_{i j}^{\min }$, w zależności od tego czy szlak $(i, j)$ należy do przeciążonych, czy też nie [12].

Nieliniowe funkcje czasu obsługi są typowe dla transportu kolejowego, zwłaszcza dla tych jego elementów (stacji, szlaków itp.), które związane są z kolejkami i na które wpływ mają zjawiska losowe. Stosowanie modeli nieliniowych dla potoków ładunków, nie wymaga wprowadzania ograniczeń dotyczących zdolności przepustowej szlaków i zdolności przeróbczej stacji w formie jawnej. Ukazane ograniczenia zaliczają się do „słabych” i przedstawione mogą być w formie niejawnej, gdyż wraz ze wzrostem wykorzystania zdolności przepustowej szlaku, czas jazdy po nim zaczyna rosnąć do nieskończoności. Wzrost nieliniowej funkcji czasu pozwala praktycznie wprowadzić ograniczenia dotyczące zdolności przepustowych i nie pozwala obciążyć elementu powyżej zadanego poziomu. Jeśli dla każdej stacji rozpatrywanej marszruty znana jest również maksymalna wielkość przeróbki, to w modelu można dodatkowo uwzględnić ograniczenia typu $N_{j} \leq N_{j}^{\max }$, gdzie $j=\overline{1 ; n}$, a $N_{j}^{\max }$ jest maksymalną zdolnością przeróbczą $j$ - tej stacji.

Tak więc przedstawienie nakładów w formie nieliniowej pozwala podejmować decyzje uwzględniające lokalne ograniczenia technologiczne. Ich istnienie potwierdza praktyka, tymczasem w badaniach dotyczących wyboru dróg przewozu ładunków w transporcie kolejowym zależności nieliniowe uwzględniane były niezwykle rzadko, co prowadziło do dodatkowych nakładów wynikających z nie wykorzystania realnych przepustowości elementów sieci.

W zadaniu wyboru marszruty należy uwzględniać czynniki, które często nie są sformalizowane i noszą charakter subiektywny. Ważnym narzędziem opisującym te czynniki są funkcje kar [5,7], które buduje się na bazie ograniczeń. Zmieniają one funkcję celu w ten sposób, że nie spełnienie ograniczeń staje się nieopłacalne. Karę nakłada się na funkcję celu w punktach, które „opuściły” lub pragną „opuścić” zbiór dopuszczalny. Funkcja kar zbudowana na granicy obszaru dopuszczalnego „uniemożliwia” wyjście rozwiązania poza ten obszar.

Rozwiązanie optymalne poszukuje się w obszarze dopuszczalnym [4].

$\mathrm{Na}$ rys. 1 przedstawiono typową funkcję kar realizowaną w formie zależności nieliniowej $C_{i j}\left(N_{i j}\right)$ 
i funkcję nakładów $f_{i j}\left(N_{i j}\right)$, gdzie $N_{i j}$ - potok ładunków na łuku $(i, j)$.

W przypadku ogólnym funkcja kar $C_{i j}\left(N_{i j}\right)$ i $C_{j i}\left(N_{i j}\right)$ dla łuku $(i, j)$ ma postać:

$$
\begin{aligned}
& C_{i j}=\left\{\begin{array}{l}
\alpha, \text { jesli } N_{i j}<0 \\
C_{i j}^{*}-\beta, \text { jesli } 0 \leq N_{i j} \leq N_{i j}^{\min } \\
C_{i j}^{1}\left(N_{i j}\right), \text { jesli } N_{i j}^{\min } \leq N_{i j} \leq N_{i j}^{\max } \\
C_{i j}^{2}\left(N_{i j}\right) \text {,jesli } N_{i j}^{\max }<N_{i j},
\end{array}\right. \\
& C_{j i}=\left\{\begin{array}{l}
-C_{i j}, \text { jesli } N_{i j}>0 \\
\alpha, \text { jesli } N_{i j} \leq 0,
\end{array}\right.
\end{aligned}
$$

gdzie: $\alpha$ - stała o dużej wartości, $\beta$ - nieskończoność umowna.

W przypadku szczególnym, funkcja kar $C_{i j}\left(N_{i j}\right) \quad \operatorname{gdy} \quad C_{i j}^{1}\left(N_{i j}\right)=C_{i j}^{*}, \quad$ a $\quad C_{i j}^{2}\left(N_{i j}\right)=C_{i j}^{* *}$ i funkcja nakładów, przy lokalnym dodatkowym ograniczeniu ,nie mniej niż $N_{i j}^{\min }$ i nie więcej niż $N_{i j}^{\max }$,, pokazane zostały na rys. 2 .

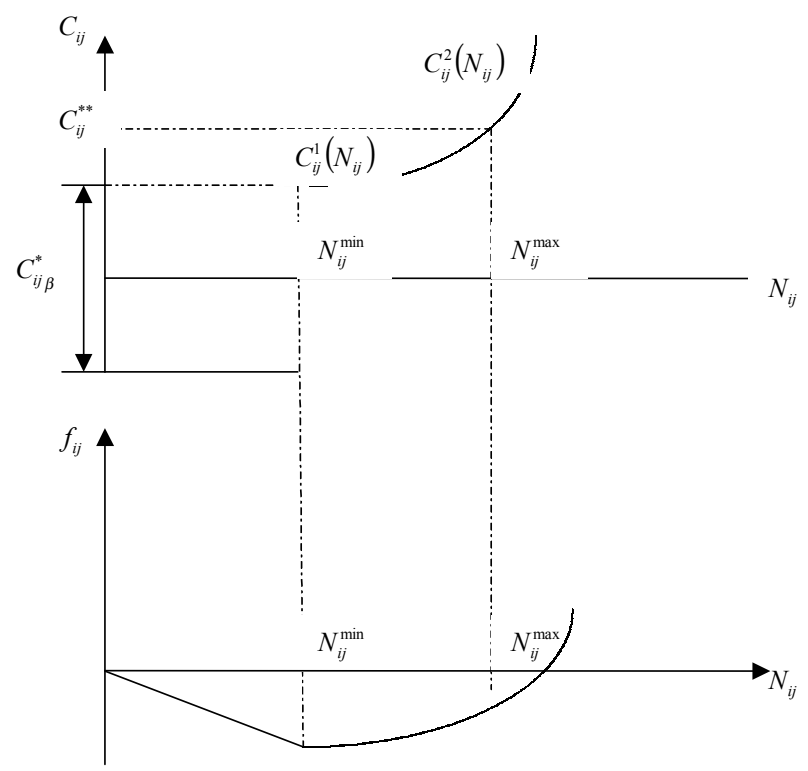

Rys. 1. Funkcja kar $C_{i j}\left(N_{i j}\right)$ i funkcja nakładów $f_{i j}\left(N_{i j}\right)$ przy ograniczeniu potoku „nie mniejszy niż $N_{i j}^{\text {min }}$ i nie większy niż

$$
N_{i j}^{\max }
$$

W interaktywnym procesie obliczeniowym, w miare pojawiania się informacji o dodatkowych ograniczeniach lokalnych związanych z potokiem wagonów, funkcje kar ulegają korekcie.

Na rys. $3 \div 5$ przedstawiono funkcje kar przy ograniczeniu potoku odpowiednio: „nie większy niż $N_{i j}^{\max }$,, „nie mniejszy niż $N_{i j}^{\min }$ ” i ,równy $N_{i j}^{*}$ ”.

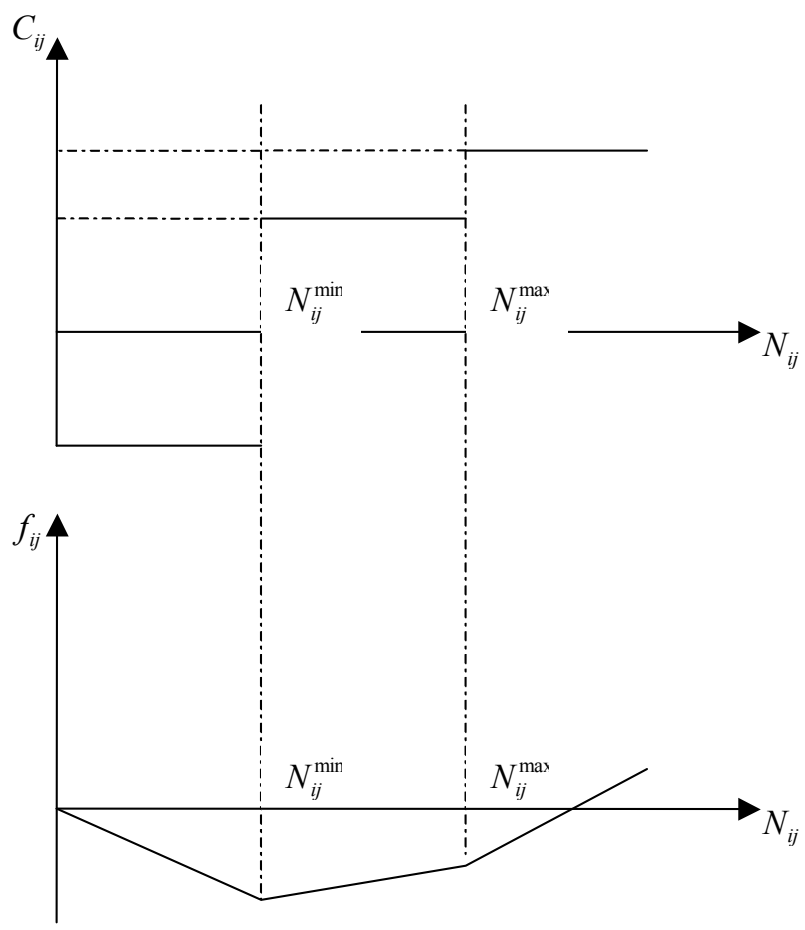

Rys. 2. Przypadek szczególny funkcji kar $C_{i j}\left(N_{i j}\right)$ i funkcji nakładów $f_{i j}\left(N_{i j}\right)$ przy ograniczeniu potoku, ,nie mniejszy niż $N_{i j}^{\min }$ i nie większy niż $N_{i j}^{\max }$,.

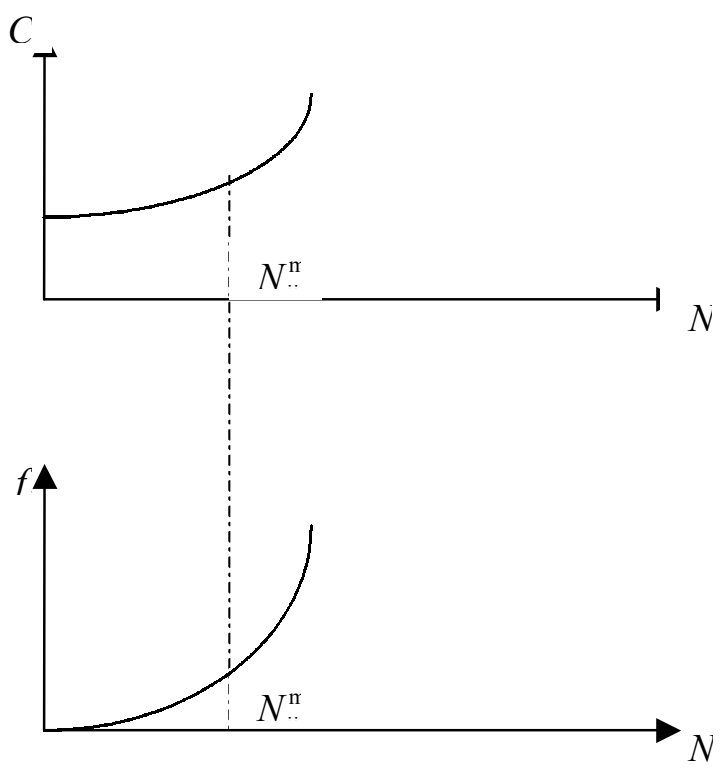

Rys. 3. Przypadek szczególny funkcji kar $C_{i j}\left(N_{i j}\right)$ i funkcji nakładów $f_{i j}\left(N_{i j}\right)$ przy ograniczeniu potoku , nie więksszy niż

$$
N_{i j}^{\max }
$$




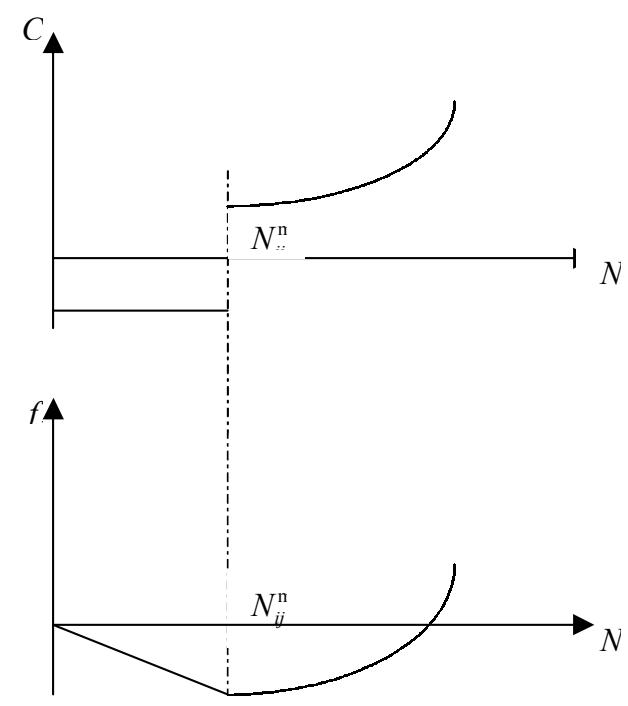

Rys. 4. Przypadek szczególny funkcji kar $C_{i j}\left(N_{i j}\right)$ i funkcji nakładów $f_{i j}\left(N_{i j}\right)$ przy ograniczeniu potoku ,nie mniejszy niż

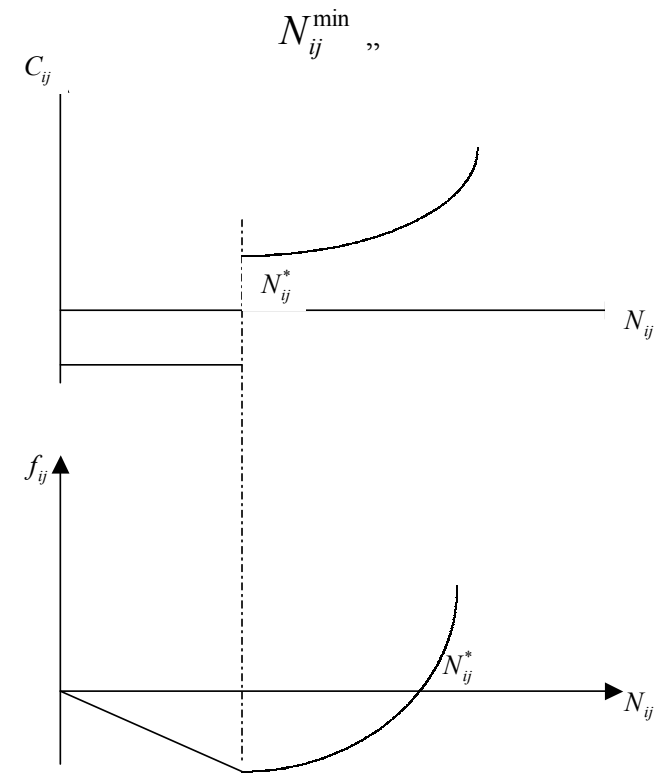

Rys. 5. Przypadek szczególny funkcji kar $C_{i j}\left(N_{i j}\right)$ i funkcji nakładów $f_{i j}\left(N_{i j}\right)$ przy ograniczeniu potoku ,równy $N_{i j}^{*}$,

Przedstawiony mechanizm sterowania nieliniowymi ograniczeniami lokalnymi pozwala, przy wyborze marszruty, uwzględnić czynniki często słabo sformalizowane.

Z przeprowadzonych powyżej rozważań wynika pilna potrzeba opracowania metody wyboru optymalnych dróg przewozu ładunków w transporcie kolejowym uwzględniającej nakłady nieliniowe. Powszechnie stosowana metoda rozkładu stopniowego [7,9], zakłada rozdzielenie potoku etapami, przy czym na każdym etapie rozkładu uwzględnia się wyniki etapu poprzedniego. Pomimo szerokiej aprobacji, metoda ta jest złożona w sensie obliczeniowym i nie spełnia ograniczeń lokalnych i technologicznych, dotyczących niepodzielności potoku.
Niniejsza praca jest pierwszą $\mathrm{z}$ cyklu prac poświęconych optymalnym i efektywnym metodom wyznaczania dróg przewozu ładunków w transporcie kolejowym.

Oryginalność zaproponowanej w nich metodyki polega na doborze adekwatnych do rzeczywistości modeli i algorytmów rozwiązujących sformułowany problem.

\section{Literatura}

[1] Акулиничев В.М. и др.: Организация вагонопотоков и маршрутизация перевозок, М., «Транспорт», 1970

[2] Deo N.: Teoria grafów i jej zastosowanie w technice $i$ informatyce, PWN, 1980

[3] Gajda B.: Technologia i automatyzacja pracy stacji, Wydawnictwo Politechniki Warszawskiej, 1983

[4] Gutenbaum J.: Modelowanie matematyczne systemów, PWN, Warszawa-Łódź, 1987

[5] Лебедев Т.П., Ломакина Н.Н., Садиков П.П., Сотников Е.А.: Расчет времени нахождения вагонов на сортировочных и участковых станциях, Труды ЦНИИ МПС, выл. 481, «Транспорт», 1973

[6] Leszczyński J.: Optymalna decyzja w procesach transportowych, WKiK, Warszawa, 1981

[7] Leszczyński J.: Modelowanie systemów i procesów transportowych, Wydawnictwo Politechniki Warszawskiej, Warszawa, 1990

[8] Лебедев Т.П., Ломакина Н.Н., Садиков П.П., Сотников Е.А.: Расчет времени нахождения вагонов на сортировочных $и$ участковых станциях, Труды ЦНИИ МПС, выл. 481, «Транспорт», 1973

[9] Левит Б.Ю., Ливиии В.Н.:Нелинейные сетевые транспортные задачи, М., «Транспорт», 1972

[10] Nowosielski L.: Procesy przewozowe $w$ transporcie kolejowym, Oficyna Wydawnicza Politechniki Warszawskiej, Warszawa, 1995

[11] Nowosielski L.: Organizacja przewozów kolejowych, Kolejowa Oficyna Wydawnicza, Warszawa, 1999

[12] Potthoff G.: Teoria potoków ruchu, WKiK, Warszawa, 1973

[13] Woch J.: Podstawy inżynierii ruchu kolejowego, WKiK, Warszawa, 1983 